Research Article

\title{
Experimental Investigation of Ground and Air Temperature Fields of a Cold-Region Road Tunnel in NW China
}

\author{
Hao Wu, ${ }^{1}$ Yujian Zhong $\mathbb{D}^{1}{ }^{1}$ Wei Xu, ${ }^{1}$ Wangshuaiyin Shi, ${ }^{1}$ Xinghao Shi, ${ }^{1}$ and Tong Liu $\mathbb{i D}^{2}$ \\ ${ }^{1}$ School of Highway, Chang'an University, Xi'an 710064, China \\ ${ }^{2}$ School of Science, Xi'an University of Architecture and Technology, Xi'an 710055, China
}

Correspondence should be addressed to Yujian Zhong; zhongyujian@chd.edu.cn and Tong Liu; liutong@xauat.edu.cn

Received 24 November 2019; Revised 23 June 2020; Accepted 1 July 2020; Published 22 July 2020

Academic Editor: Claudio Mazzotti

Copyright $\odot 2020$ Hao Wu et al. This is an open access article distributed under the Creative Commons Attribution License, which permits unrestricted use, distribution, and reproduction in any medium, provided the original work is properly cited.

To fully understand the temperature distribution of cold regions and the variation law of temperature fields in cold-region tunnels, this paper presents a case-history study on a tunnel located on the eastern Qinghai-Tibet Plateau, China. The conclusion is as follows: the temperature outside the tunnel and the ambient temperature are affected by wind speed and light. The law of the temperature field in the tunnel is greatly affected by wind speed and wind direction. According to the field test, the wind speed in the tunnel is about $2.8 \mathrm{~m} / \mathrm{s}$ in winter, and the daily average temperature at the exit of the tunnel is basically lower than that at the entrance. From the central to the entrance, the temperature in the tunnel decreases by $0.11^{\circ} \mathrm{C}$ every 10 meters along the longitudinal direction; from the central to the exit, the temperature in the tunnel increases by $0.07^{\circ} \mathrm{C}$ every 10 meters. In this regard, for the problems of lining frost damage and central drainage pipe freezing, it is suggested to adopt the way of heating and drainage, but heating the freezing area outside the drainage pipe should be avoided. The test results can provide references for the design, construction, and research of the temperature field of the tunnel antifreezing system in the cold region. It is hoped that the test results can be useful in the design and construction of frost damage prevention systems and the investigation of temperature fields in cold-region tunnels.

\section{Introduction}

Permafrost regions account for approximately $23 \%$ of Earth's surface, mainly in Russia, Canada, China, and the US state of Alaska [1-3]. Of these regions, the permafrost regions in China, which account for approximately $10 \%$ of Earth's surface, represent the world's third-largest permafrost area. China's permafrost regions are primarily distributed in the Tibetan Plateau, which is known as the world's "third pole." Additionally, seasonal frozen-ground regions in China, which account for approximately $53.5 \%$ of the nation's total land area, are distributed in the centrenorth. Tunnelling in cold regions changes the thermal balance of rock masses. However, the temperature range in which cold-region engineering is practiced is significantly influenced by the thermal conductivity of the soil-rock media, which is related to engineering problems caused by frost heave [4-6]. Generally, when frost heave occurs because of low temperatures, the properties of the rock mass change, and frost deformation significantly affects tunnel stability. Frost damage, such as peeling, lining surface fractures, seepage, icing, slippery collapse, and tunnel freeing port freezing, is primarily caused by freeze-thaw cycles. The substantial difference in air temperature between morning and evening significantly weakens service capacity and life.

In Northeast China, the Baikal tunnel, Xiluo tunnel, and Cuiling tunnel. The Yuximolgai tunnel built in Xinjiang have ice jam due to the impact of low temperature and frost damage. The thickest ice accumulated in the tunnel is more than 1.6 meters, which results in the impassable of the tunnel every winter [7]. Cold-region tunnels that suffer cold damage are widely distributed in China (Figure 1). To ensure the normal operations of such tunnels, a substantial quantity of manpower, material, and financial resources are required. Cold damage results in substantial monetary losses for the government $[8,9]$. Thus, research on cold-region tunnels is highly important. 


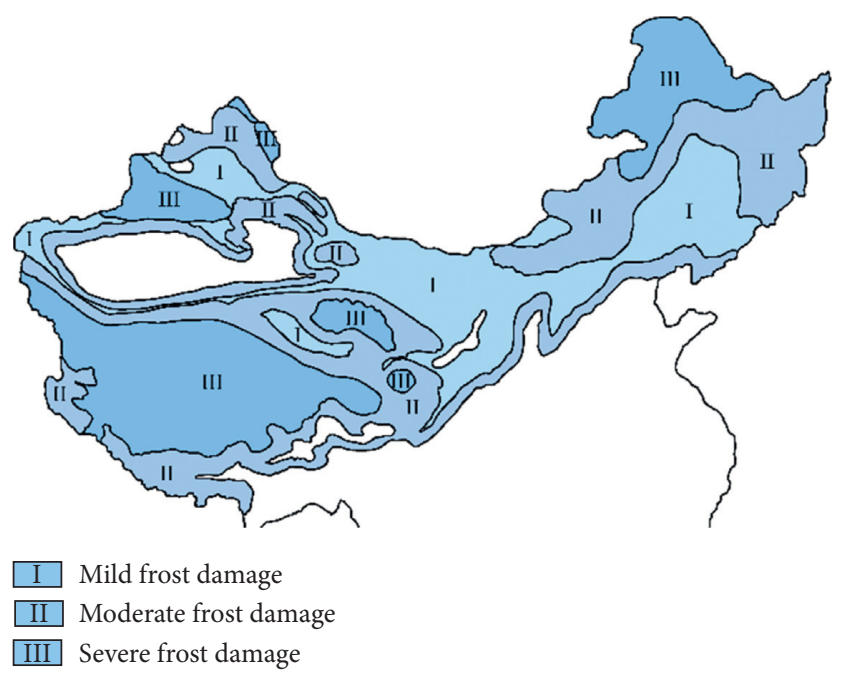

Figure 1: Distributions of frost damage in China.

In a subzero temperature environment, tunnels generate a few problems. Although numerous studies on cold-region tunnels have been conducted in recent decades [10-12], the frost-heaving force in rock masses and the ground and air temperature fields have been insufficiently analysed. To understand the temperature distribution of cold regions and the variation law of temperature fields in cold-region tunnels, the meteorological conditions in cold regions and the ground temperature in the tunnels must be measured systematically [13-15]. The following results for different aspects of cold-region tunnels have been obtained. For instance, in the US, the Cold Regions Research and Engineering Laboratory (CRREL) $[16,17]$ has obtained a series of valuable research results based on a long-term (since 1963) temperature observation of permafrost tunnels. Using 1974 meteorological data for New Delhi, Bansal et al. [18] studied the annual variation of the ground temperature distribution for different surface conditions in warm regions. Using a test tunnel in the cold region of the Heilongjiang Province, China, Li [19] determined a temperature distribution curve for in- and outside the tunnel. He et al. [20] studied the freezing and thawing of the rock that surrounds the tunnels in cold regions, employing a combined convection-conduction model of turbulent airflow in tunnels. Lai et al. [21] performed nonlinear analyses for the coupled problem of temperature and seepage fields in cold-region tunnels using Galerkin's method. Through numerical investigation, field testing, and local data observation, Goreing and Kumar [22] investigated the protective effect of a riprap embankment on permafrost. According to the measured temperature fields in a cold-region tunnel, Yan et al. [23] analysed the law that regulates the annual and daily temperature in- and outside the tunnel. Considering the temperature variations according to coordinates, Qin et al. [24, 25] and Prashantk $[26,27]$ employed the superposition principle and the variable separation approach to obtain analytical solutions for a transient temperature field in a multilayer cylinder under the convective boundary condition. Based on the extensive testing of inner and outer tunnel temperature fields, Chen and Zan [28, 29] determined the temperature change regularity and the change characteristics of the maximum frozen soil depth.

To the best of our knowledge, the construction of tunnels in cold regions is a difficult task. It is of positive significance for the design of the tunnel structure to master the variation law of the ground temperature and air temperature field. However, the conclusion of the law of ground temperature and air temperature field cannot be based on a single tunnel in the cold region. We need to monitor and summarize the temperature field of many tunnels in cold regions. To understand the freezing and thawing of the rock mass and the distribution of the air temperature in- and outside such tunnels and to provide reference data for practical engineering designs, this paper presents a case study on a coldregion tunnel. Based on the long-term field testing at the Qingshashan tunnel, China, 14 test sections were selected. In addition, a regressive analysis of the temperature field data was conducted. The analysis included the inside and surface temperature fields of the liner, the rock mass temperature field, and the air temperature field. Specifically, the relationship between the temperature in the tunnel and the outer atmospheric temperature is discussed. Additionally, the temperature's longitudinal variation curve without mechanical ventilation in the tunnel is presented.

\section{Project Overview}

The Qingshashan tunnel on the Tibetan Plateau, China (Figure 2), was constructed as part of a highway improvement program from Pin'an to Adai. The tunnel is a separated tunnel with traffic lanes that run in opposite directions. The Qingshashan tunnel is the longest highway tunnel in Qinghai Province. The tunnel's two traffic pathways are $3350 \mathrm{~m}$ and $3340 \mathrm{~m}$ long, respectively. The Qingshashan tunnel section looks like horseshoe, and the clear width and height of tunnel construction clearance are $9.25 \mathrm{~m}$ and $5.0 \mathrm{~m}$, respectively. The tunnel is in the Qingshashan area belonging to the denudation of mountain topography, where the elevation ranges from $3004.59 \mathrm{~m}$ to $3398.81 \mathrm{~m}$, and the highest height difference is approximately $354 \mathrm{~m}$. The climate is that of a typical continental semiarid plateau. The Qingshashan tunnel is in an area in which the seasonal frost depths are between moderate and deep and receives moderate frost damage [30]. The ground of the Qingshashan area is a typical seasonal frozen ground with alpine meadows as the dominant vegetation type and with complicated topography, steep slope, water erosion, U-shaped gully development, and a substantial temperature difference between morning and evening. The winters are bitterly cold and long, whereas the summers are cool. Based on long-term historical meteorological data, the mean annual air temperature is $5.90^{\circ} \mathrm{C}$, the extreme high temperature is $38.70^{\circ} \mathrm{C}$, the extreme low temperature is $-26.60^{\circ} \mathrm{C}$, and the maximum frost depth is approximately $1.48 \mathrm{~m}$. Rainfall in this area increases with the gradually rising terrain, with a mean annual rainfall of approximately $500 \mathrm{~mm}$ and a mean annual evaporation of $1,636 \mathrm{~mm}$, which primarily occurs from June to September. Southeast winds are typical, and the average 


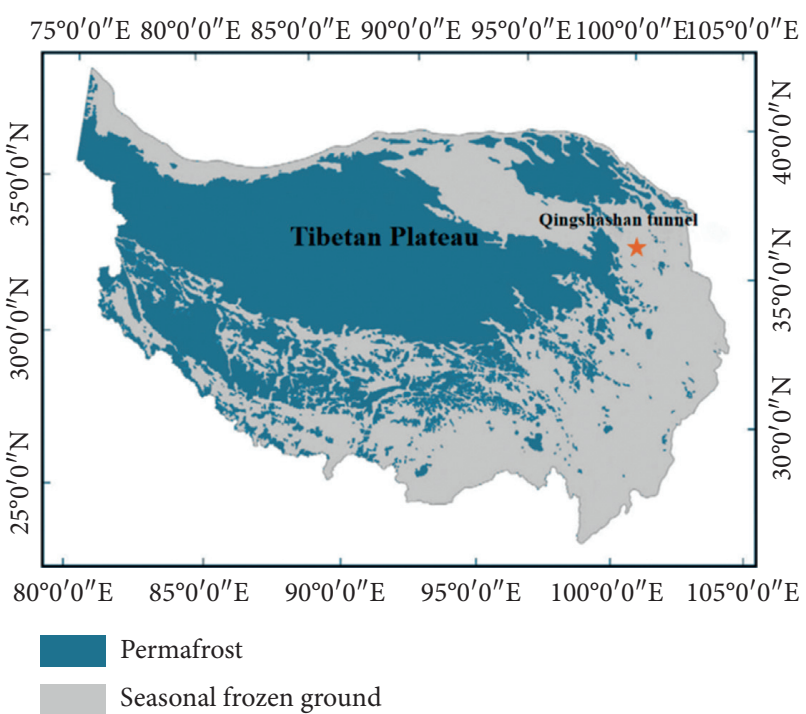

Figure 2: The location of the Qingshashan tunnel in the Tibetan Plateau and distribution of permafrost.

wind speed is $1.8 \sim 3.9 \mathrm{~m} / \mathrm{s}$. Additionally, there are large numbers of faults in the tunnel location, and the fissure phreatic water is primarily distributed in the fractured fault zone, whose water yield property is medium. The tunnel excavation area is rich in water, and there is a risk of frost damage in the tunnel.

\section{Methods and Instrumentation}

3.1. Ground Temperature Monitoring. After a tunnel is opened through a mountain, the convection of air in the tunnel changes the initial thermal balance of the rock that surrounds the tunnel. That is, freezing and thawing occurs in the tunnel rock mass because of the change of air temperature in the tunnel. Because the ground temperature field can provide a beneficial reference for the design of tunnel antifreezing insulation, we installed submerged platinum metal thermistors (JMT-36X) (Figure 3) at equal radial intervals along the tunnel to monitor the ground temperature. As shown in Figure 4, the JMZX200X comprehensive tester was used with the temperature sensors. The JMT-36X temperature sensor is a new type of sensor with high accuracy, high stability, high reliability, moisture-proof, and good insulation. It is often used in large-scale projects such as railway and highway. Its sensitivity is $0.1^{\circ} \mathrm{C}$, accuracy is within $\pm 0.5^{\circ} \mathrm{C}$, and its range is $-30^{\circ} \mathrm{C} \sim+120^{\circ} \mathrm{C}$. Thermometric elements, which were longitudinally installed along the tunnel in symmetrical distribution, were buried in the tunnel's rock masses to measure the temperature of the rock. Their locations are shown in Figure 5. The distance between the thermometric element (number) and the liner surface is detailed in Table 1. Additionally, considering that the temperature data of the left tube were seriously affected by tunnelling, only the temperature data of the Qingshashan tunnel's right tube were analysed. The temperature was monitored every six hours: 2:00 am, 8:00 am, 2:00 pm, and 8: $00 \mathrm{pm}$.

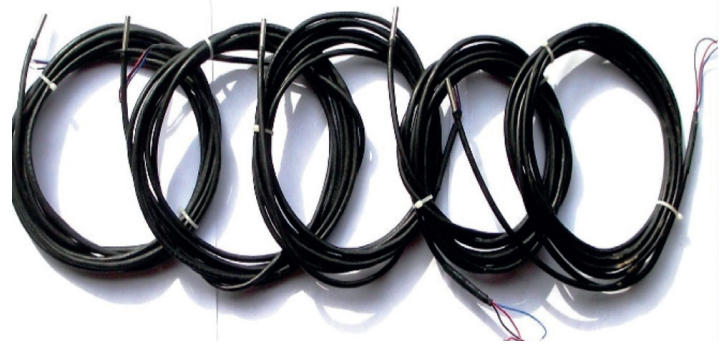

FIgURE 3: JMT-36X temperature sensors assemblies.

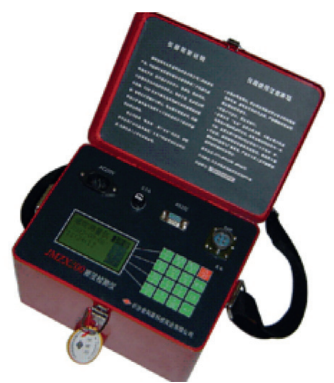

Figure 4: JMZX200X comprehensive tester.

3.2. Air Temperature Monitoring. The air temperature inand outside the tunnel was recorded automatically using a temperature and humidity automeasurement system (ZJI2B) (Figure 6) and was corrected strictly in accordance with the requirements. The accuracy of temperature range of the ZJI-2B weekly temperature hygrometer is $\pm 1^{\circ} \mathrm{C}$, and its accuracy of humidity range is $\pm 5 \% \mathrm{RH}$. To measure the significant temperature change that occurs outside the tunnel, thermohygrometers were installed at the tunnel portals and at sites in the tunnel $500 \mathrm{~m}$ from the entrance. Additionally, a thermohygrometer was installed in the middle section of the tunnel, and outdoor thermohygrometers were installed outside the tunnel according to the meteorological requirements, i.e., at sites outside the tunnel and $50 \mathrm{~m}$ from the entrance and exit. Moreover, the outdoor thermohygrometers were placed in shelters that were $1.5 \mathrm{~m}$ high and distant from obstacles to obtain free-moving air standard values, whereas the thermohygrometers in the tunnel were suspended from the liner surface at the height of $1.5 \mathrm{~m}$ to reduce sensitivity to temperature and interference from dust. According to international meteorological test practices, the temperature was monitored every six hours: 2 : $00 \mathrm{am}, 8: 00 \mathrm{am}, 2: 00 \mathrm{pm}$, and 8:00 pm [31]. The longitudinal distribution of the thermohygrometers along the tunnel is shown in Figure 7.

\section{Results}

\subsection{Discussion of the Ground Temperature Field}

4.1.1. Ground Temperature of All Testing Sections. The ground temperature distribution at the different testing sections over time is shown in Figures $8(\mathrm{a})-8(\mathrm{f})$. It can be observed that the ground temperature distribution, which 


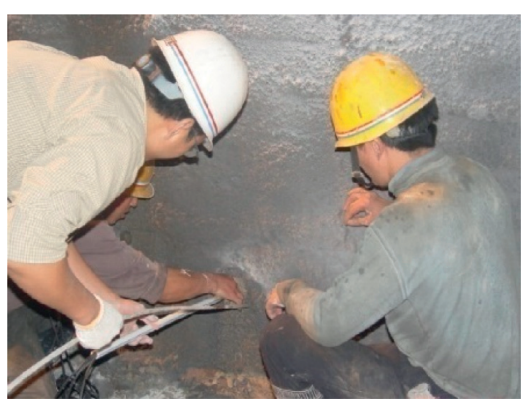

(a)

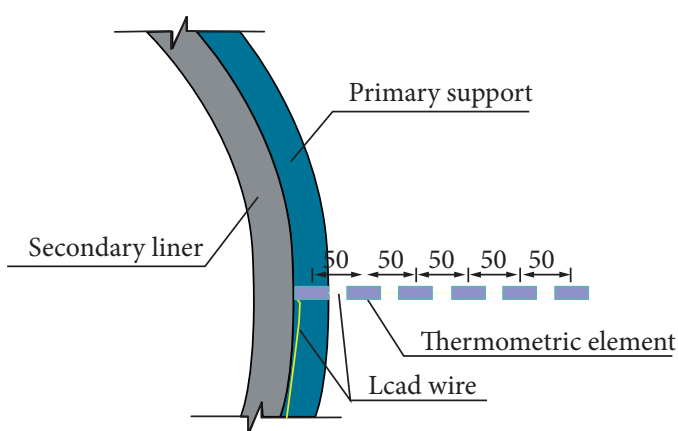

(b)

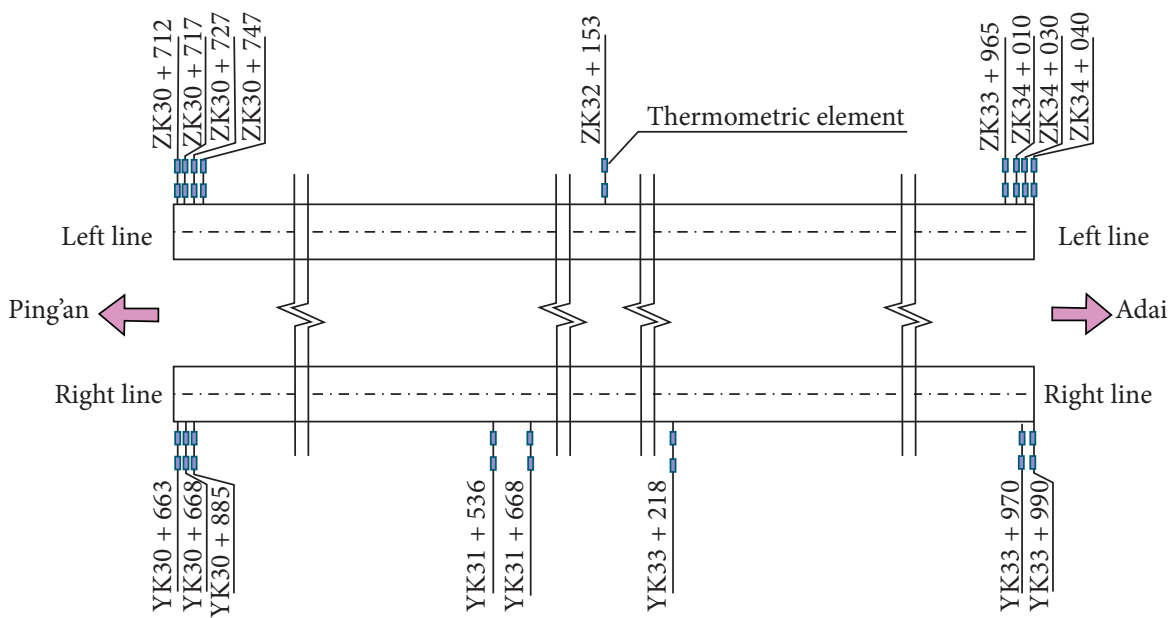

(c)

Figure 5: Distribution of thermometric elements. (a) Field installation of temperature sensors. (b) The radial distribution of thermometric elements. (c) Distribution of thermometric elements in longitude along the tunnel.

TABLE 1: The distance between thermometric elements and the liner surface.

\begin{tabular}{|c|c|c|c|c|c|c|c|c|c|c|}
\hline (a) & & & & & & & & & & \\
\hline Line length (number) & $1.0 \mathrm{~m}$ & $1.5 \mathrm{~m}$ & $2.0 \mathrm{~m}$ & $2.5 \mathrm{~m}$ & $3.0 \mathrm{~m}$ & $6.5 \mathrm{~m}$ & $7.0 \mathrm{~m}$ & $7.5 \mathrm{~m}$ & $8.0 \mathrm{~m}$ & $8.5 \mathrm{~m}$ \\
\hline Distance $(\mathrm{m})$ & 1 & 1 & 2 & 2 & 3 & 1 & 1 & 2 & 0 & 3 \\
\hline \multicolumn{11}{|l|}{ (b) } \\
\hline Line length (number) & $1.0 \mathrm{~m}$ & $1.4 \mathrm{~m}$ & $1.8 \mathrm{~m}$ & $2.2 \mathrm{~m}$ & $2.6 \mathrm{~m}$ & $3.0 \mathrm{~m}$ & & & & \\
\hline Distance $(\mathrm{m})$ & 0.5 & 0.9 & 1.3 & 1.7 & 2.1 & 2.5 & & & & \\
\hline
\end{tabular}

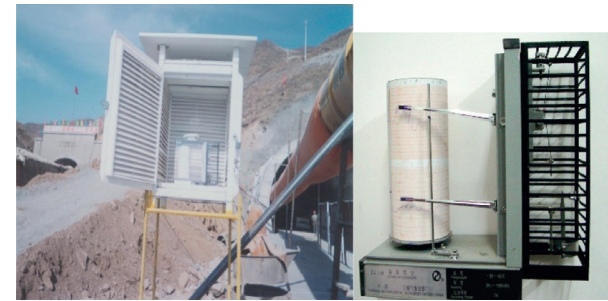

FIGURE 6: ZJI-2B intelligent thermohygrometer.

consists of reading from sites $3 \mathrm{~m}, 8 \mathrm{~m}$, and $23 \mathrm{~m}$ from the entrance and sites $5 \mathrm{~m}$ and $15 \mathrm{~m}$ from the exit, can be divided into three stages based on time. The first stage is from November of the previous year to early April of the second year. The deeper the surrounding rock is buried, the higher the measured temperature value is. In this period, the temperature after the tunnel lining and within the range of
$0.5 \mathrm{~m}$ surrounding rock has been negative. In the coldest February, the negative temperature also occurs for a long time in the depth of $1 \mathrm{~m}$ surrounding rock. The second section is from the beginning of April to the middle of August, during which the temperature in the surrounding rock can be regarded as from negative to positive and then reaches the highest temperature in the whole year. The third stage is from the middle of August to November. The rate of temperature decrease is faster than that of temperature rise, so the curve of temperature decrease is steeper than that of temperature rise.

Similarly, the ground temperature distribution along the tunnel (the sites in the tunnel that are $876 \mathrm{~m}$ and $1000 \mathrm{~m}$ from the entrance and the site that is $800 \mathrm{~m}$ from the exit) can also be divided into three stages based on time.

The first stage is from November of the first year to the end of March of the next year. In this stage, the temperature 


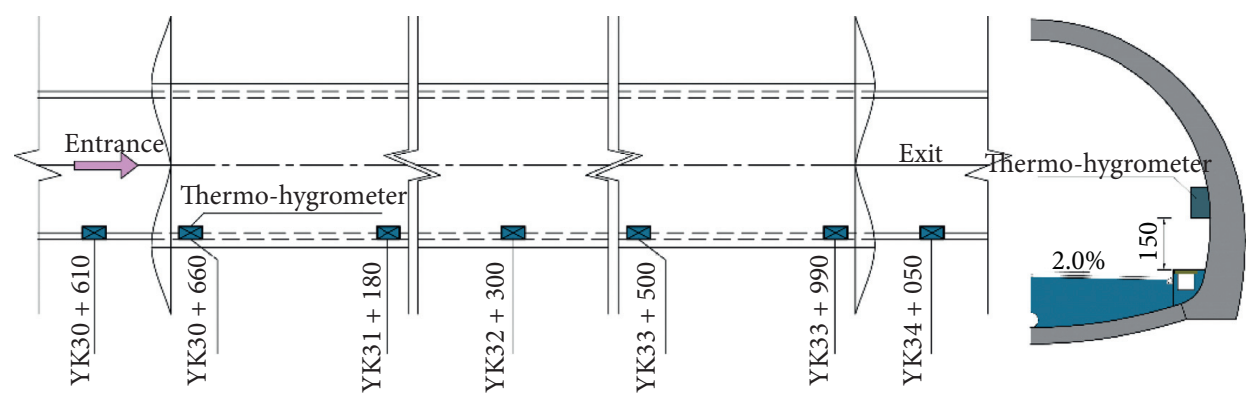

FIGURE 7: Distribution of thermohygrometers in longitude along the tunnel.

in the tunnel is the lowest, but the temperature in the tunnel is quite different from that measured in the surrounding rock. The second stage is from the beginning of April to the middle of July. During this period, the surrounding rock temperature rises sharply, the temperature value is unstable, and the beating is frequent. The temperature curve of each measuring point in the surrounding rock is readjusted according to the position. In winter, the curve of the low temperature rises to the highest temperature, and the curve of the highest temperature reaches the lowest temperature. The third stage is from the middle of July to November. The temperature drop curve in the surrounding rock at the entrance of the tunnel is synchronous with the change of the atmospheric temperature in the tunnel area, while the temperature in the surrounding rock at the exit of the tunnel lags behind the temperature in the tunnel.

The lowest temperature of the testing sections and the corresponding time is listed in Tables 2 and 3. The lowest temperature of section $\mathrm{K} 31+668$ is lower than that of section $\mathrm{K} 33+218$, which is contrary to what is generally assumed. The primary reason for this lower temperature is that the natural wind blows from the exit to the entrance during winter. In addition, the distance between section $\mathrm{K} 31+668$ and the entrance is longer than that between section $\mathrm{K} 33+218$ and the exit, which can easily lead one to assume that the temperature of section $\mathrm{K} 33+218$ should be significantly lower than that of section $\mathrm{K} 31+668$. From our analysis, the reason for this phenomenon is that the water storage in the rock mass near section $\mathrm{K} 33+218$, which is likely groundwater, is abundant.

4.1.2. Longitudinal Distribution of Ground Temperature. The line length of the thermometric elements with burial depths of $0.5 \mathrm{~m}, 1.0 \mathrm{~m}, 1.5 \mathrm{~m}, 2.0 \mathrm{~m}$, and $2.5 \mathrm{~m}$ is $1.0 \mathrm{~m}, 1.5 \mathrm{~m}$, $2.0 \mathrm{~m}, 2.5 \mathrm{~m}$, and $3.0 \mathrm{~m}$, respectively. In addition, the test results of the thermometric elements with burial depths of $1.5 \mathrm{~m}, 2 \mathrm{~m}, 2.5 \mathrm{~m}$, and $3 \mathrm{~m}$ are shown in Figures 9(a)-9(d). A comparison of Figure 9(a) with Figure 9(b) reveals that the ground temperature distribution on the interior of the liner always appears in an inverted $U$ shape from November of the previous year to May of the following year. Additionally, overall, the temperature of the rock masses gradually increases from the tunnel portal to the middle of the tunnel. However, the ground temperature of the section that is $10 \mathrm{~m}$ from the exit is lower than that at the tunnel exit. Moreover, the temperature increase curves present an overall trend of a small increase at the entrance and a large increase at the exit. Furthermore, the ground temperature at the entrance is slightly higher than at the exit when the air temperature is very low, and the ground temperature at the entrance is lower than at the exit when the air temperature is very high. The main reasons for this phenomenon are that the tunnel exit only has one air inlet and that the distance between section $\mathrm{K} 31+536$ and the entrance is longer than that between section $\mathrm{K} 33+218$ and the entrance.

An exception to this pattern appears in the temperature curve of section $\mathrm{K} 31+536$ with the line length that ranges from $2 \mathrm{~m}$ to $3 \mathrm{~m}$ : the ground temperature of section $\mathrm{K} 31+536$ is lower than that of the same depth at the tunnel entrance and at a shallow depth in the same section when the air temperature is very low. However, the ground temperature of this section rapidly rises with the increasing air temperature after April. From our analysis, this phenomenon occurs because there is a substantial quantity of underground water at this area around the depth of $2.0 \sim 3.0 \mathrm{~m}$ which may have infiltrated from the land surface. In addition, based on design drawings, on-site geological data, and construction records, the thermometric elements with the line length that ranges from $2 \mathrm{~m}$ to $3 \mathrm{~m}$ pass precisely through a fault. The water in the fault originates in a surface water source. The thermometric elements with the line length that ranges from $1 \mathrm{~m}$ to $1.5 \mathrm{~m}$ are installed outside the fault.

From the longitudinal ground temperature curves, we can see that the curves are relatively dense in all of the testing sections near the tunnel entrance, except section $\mathrm{K} 31+536$, because the temperature centralization of the measuring lines is acceptable and the monthly measured temperature difference is low. However, at the tunnel exit, the temperature curves tend to become more intensive with the increase in the burial depth of the thermometric elements and the increase in the distance between testing sections and the tunnel exit, which is consistent with theory and practice. In addition, there are obvious differences between the exit and the entrance, and the primary reasons for which are as follows: (1) the natural wind continually blows from the exit to the entrance. Thus, the temperature curves tend to be more intensive from the exit to the entrance. (2) The entrance of the tunnel's right tube, which is used as a construction passage for the left tube, has a tremendous effect on the temperature in the tunnel. Therefore, the wind direction 


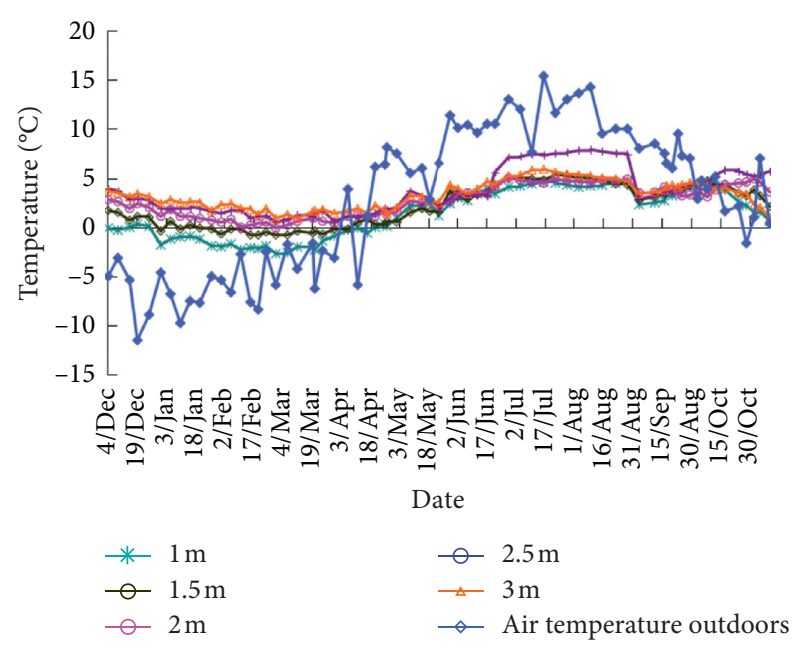

(a)

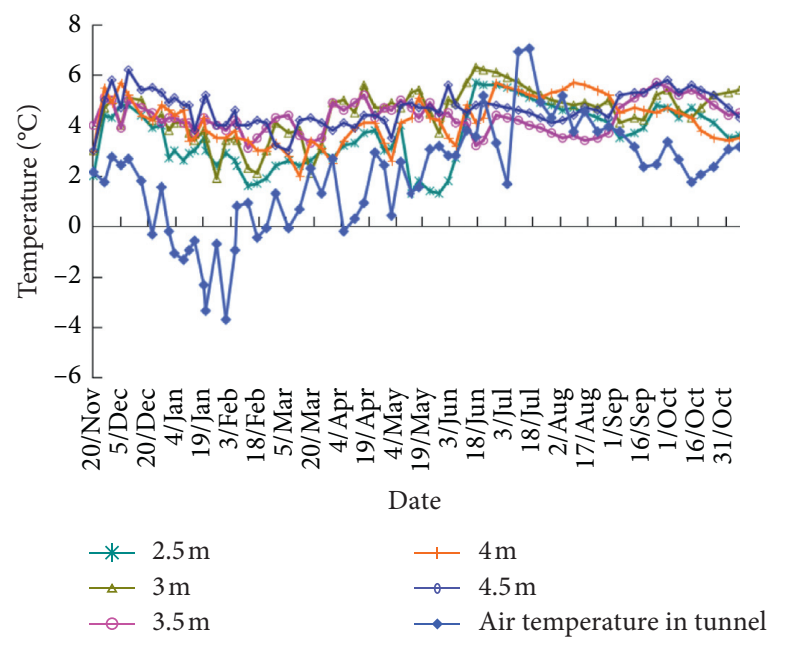

(c)

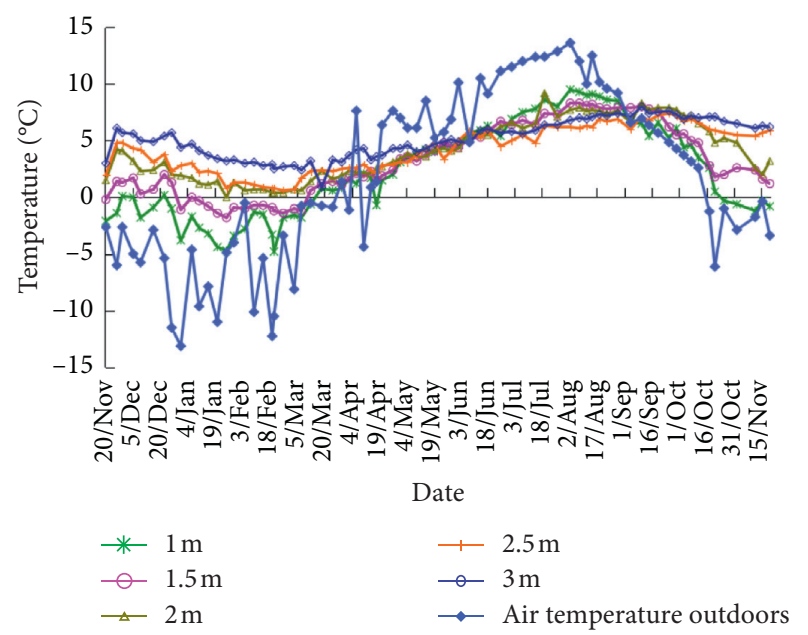

(e)

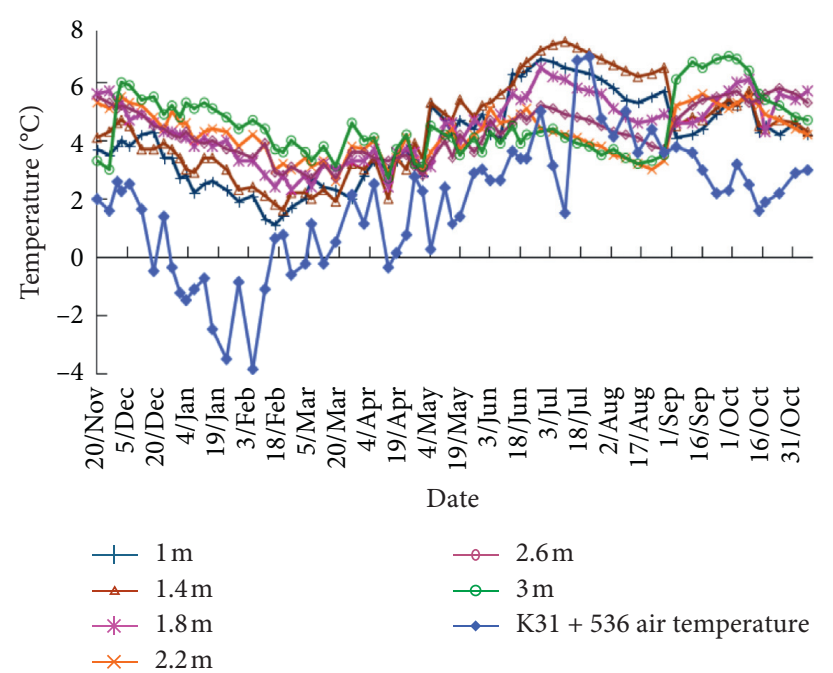

(b)

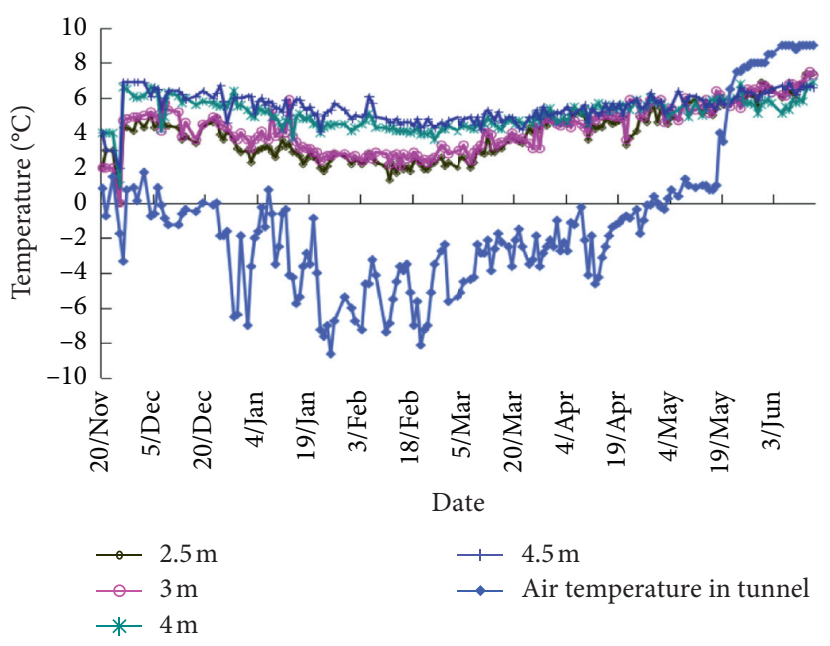

(d)

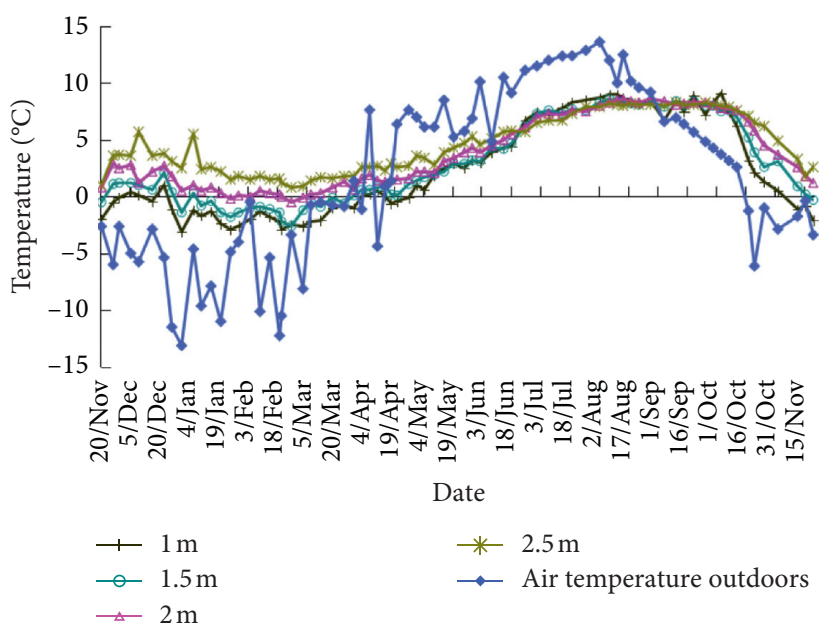

(f)

Figure 8: The ground temperature curves at different locations and testing sections vs. time. (a) Section K30 + 663. (b) Section K31 + 536. (c) Section K31 + 668. (d) Section K33 + 218. (e) Section K33 + 970. (f) Section K33 + 990 . 
TABLE 2: Minimum negative temperature of testing sections.

\begin{tabular}{lccccc}
\hline Mileage & $\mathrm{K} 30+663$ & $\mathrm{~K} 30+668$ & $\mathrm{~K} 30+683$ & $\mathrm{~K} 33+970$ & $\mathrm{~K} 33+990$ \\
\hline Date & $3 / 4$ & $3 / 8$ & $3 / 18$ & $1 / 24$ & $3 / 10$ \\
The lowest temperature $\left({ }^{\circ} \mathrm{C}\right)$ & -3.2 & -2.5 & -0.9 & -4.8 & -3.3 \\
\hline
\end{tabular}

TABLE 3: Minimum temperature of testing sections.

\begin{tabular}{lcccc}
\hline Mileage & K31+536 & K31+668 & K33+218 left & K33+218 right \\
\hline Date & $2 / 17$ & $2 / 17$ & $2 / 24$ & $2 / 24$ \\
The lowest temperature $\left({ }^{\circ} \mathrm{C}\right)$ & 0.9 & 0.8 & 1.6 & 1.8 \\
\hline
\end{tabular}

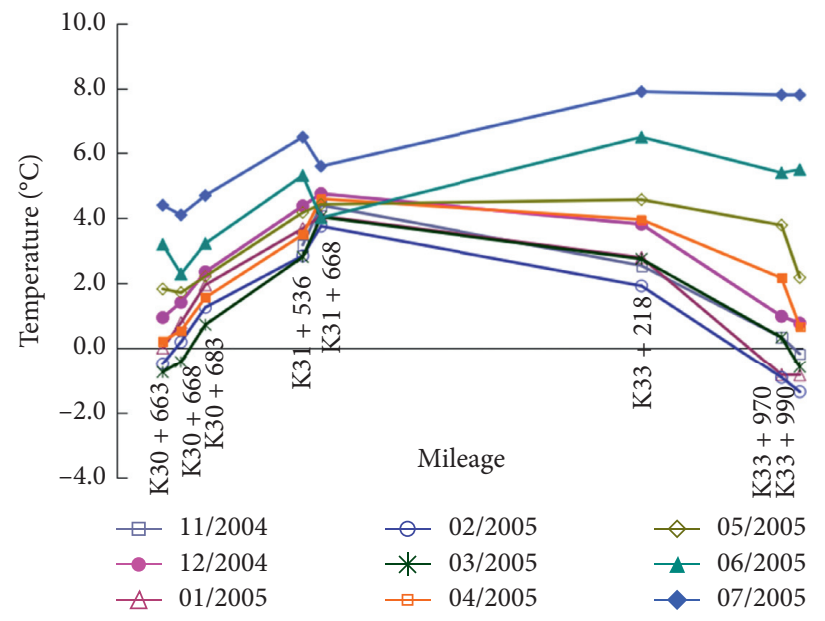

(a)

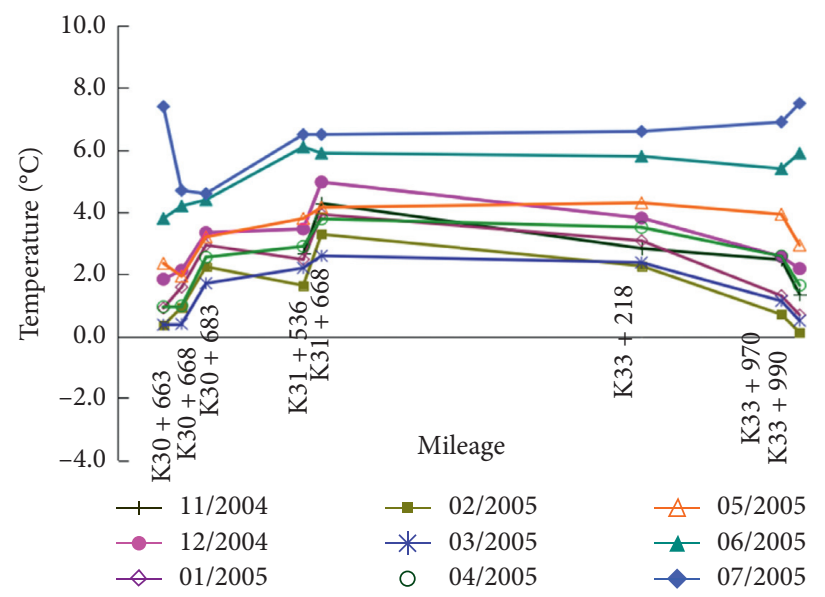

(c)

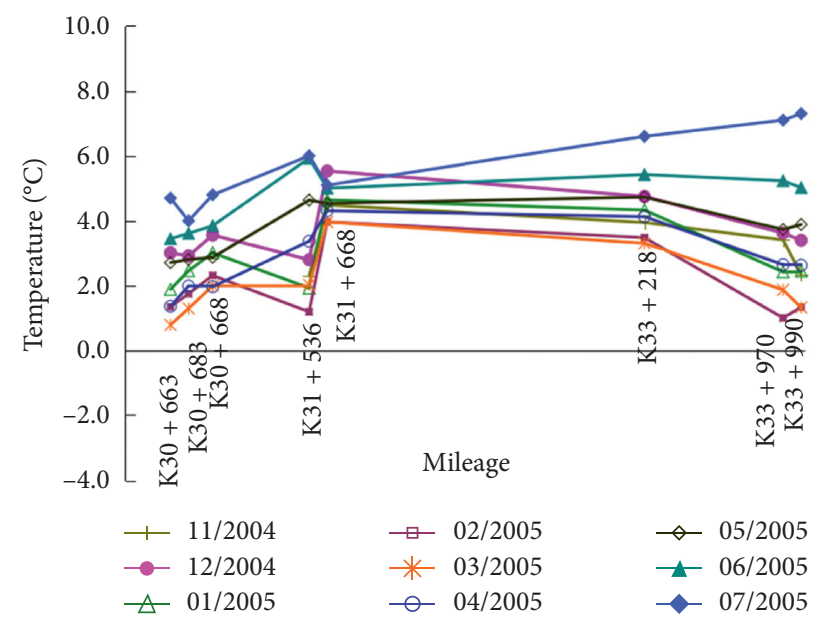

(b)

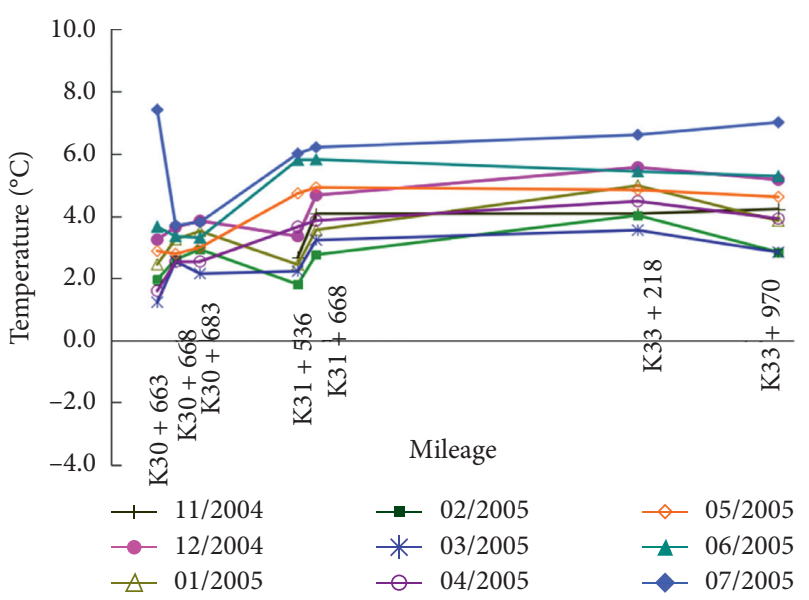

(d)

Figure 9: The ground temperature distribution at different depths along the tunnel. (a) Ground temperature at the depth of $1.5 \mathrm{~m}$. (b) Ground temperature at the depth of $2.5 \mathrm{~m}$. (c) Ground temperature at the depth of $2 \mathrm{~m}$. (d) Ground temperature at the depth of $3 \mathrm{~m}$.

in the tunnel is the key parameter that affects the ground temperature distribution.

4.1.3. Radial Distribution of Ground Temperature. The radial temperature curves of the rock masses in February and July are shown in Figures 10(a)-10(d) since those months are the coldest and the hottest ones among the entire year, respectively, It is important to note that the temperature curves in the other months are omitted for brevity which have similar change trends and ranges. The test results indicate that with the increase in the depth of the rock mass, the temperature gradually increases, and that the temperature increment in the shallow of the rock mass is slightly larger than in the deep site.

As shown in Table 4, the maximum negative air temperature and the maximum negative ground temperature are not in the same section. Although the entrance is located on the right side of the mountain, its maximum depth of the negative temperature is less than that at the exit. The primary 

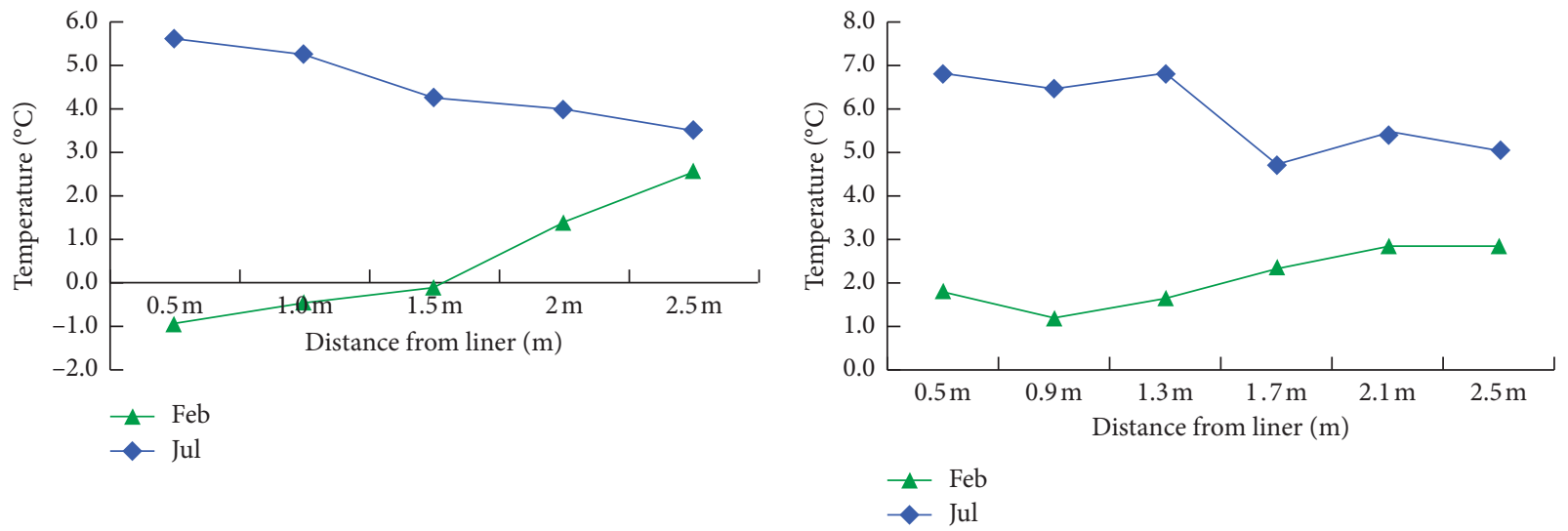

(a)

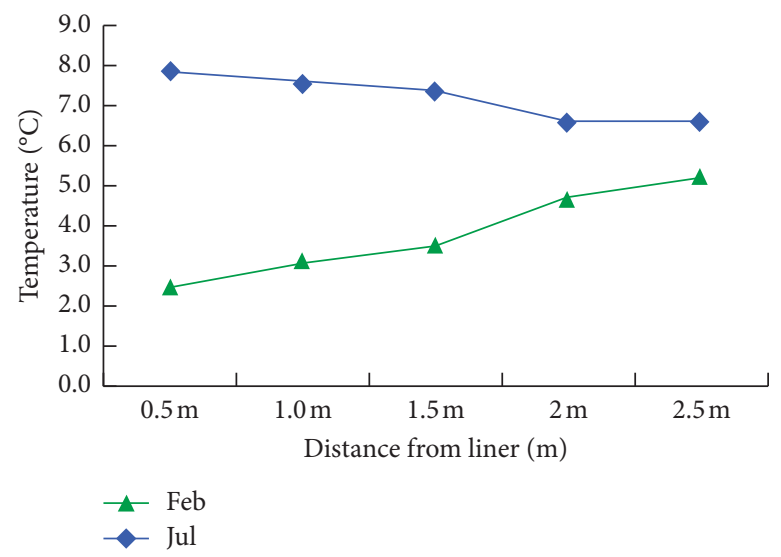

(b)

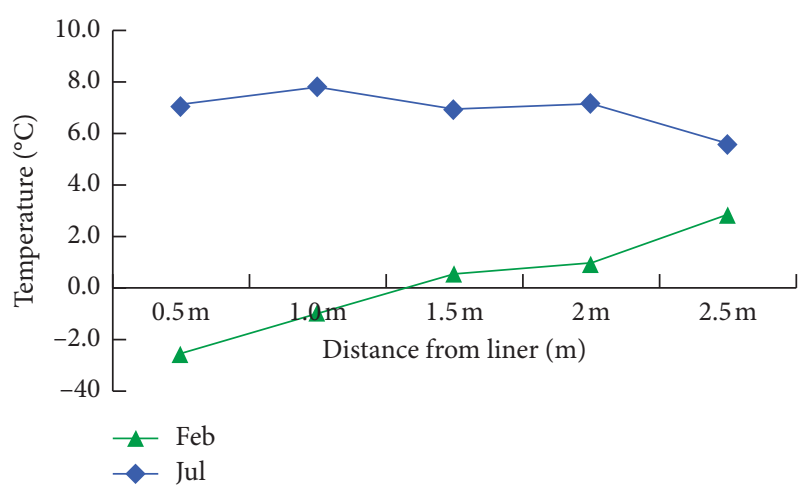

(c)

(d)

FIGURE 10: The radial temperature distribution of surrounding rock in February and July. (a) Section K30 + 668. (b) Section K31 + 536. (c) Section K33+218. (d) Section K33+970.

TABLE 4: The maximum freeze depth in the tunnel.

\begin{tabular}{lccccc}
\hline Mileage & $\mathrm{K} 30+663$ & $\mathrm{~K} 30+668$ & $\mathrm{~K} 30+683$ & $\mathrm{~K} 33+970$ & $\mathrm{~K} 33+990$ \\
\hline The maximum frost depth $(\mathrm{m})$ & 1.3 & 1.5 & 1.25 & 1.35 & 1.48 \\
\hline
\end{tabular}

reason is that the exit is the tunnel's air inlet, and the temperature distribution is influenced by the tunnelling.

When the air temperature outside the tunnel is high, the thermometric elements close to the tunnel portal are nearly at the same temperature only with a small fluctuation. The temperature in the tunnel's middle section also remains consistent. However, the temperature fluctuation of the elements at the entrance and the exit is large, which indicates that the air temperature at the entrance and the exit is unstable. Section K33 +218 is located at the tunnel exit and experiences minor construction interference. The two measured temperature curves are highly regular. Thus, they can be used to predict the average temperature of the rock masses.

\subsection{Discussion of the Air Temperature Field}

4.2.1. Air Temperature outside the Tunnel. As shown in Figure 11, the air temperature near the tunnel entrance is

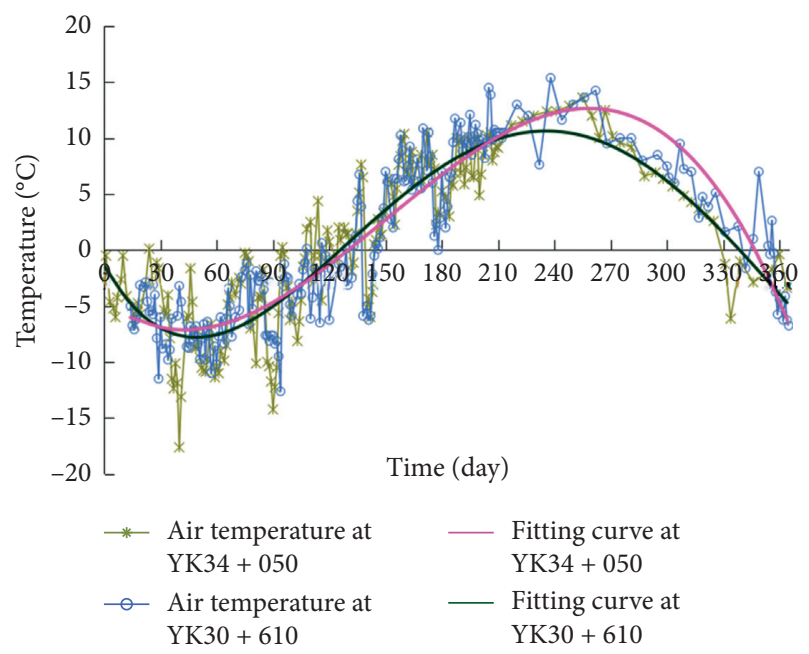

FIgURE 11: The air temperature curves outside the tunnel vs. time. 
lower than that near the tunnel exit throughout the year. The average temperature difference between the entrance and the exit reaches its maximum value when the air temperature decreases to its lowest, and the maximum difference is approximately $4^{\circ} \mathrm{C}$. According to the annual wind direction monitored in the tunnel, the natural wind blows from the tunnel exit to the entrance during winter, and the entrance average wind speed is approximately $2.8 \mathrm{~m} / \mathrm{s}$. In summer, the wind direction in the tunnel is uncertain with a relatively low average wind speed. The tunnel entrance and exit are located on the right side and the southern slope of the mountain, respectively, which is most likely a key parameter that influences the air motion in the tunnel. Throughout the year, the daily average temperature, which is generally below $0^{\circ} \mathrm{C}$, is sustained for 180 days at the exit and 165 days at the entrance.

4.2.2. Air Temperature inside the Tunnel. As shown in Figures 12(a) and 12(b), the air temperature difference between the entrance and exit is large during the coldest month. On the one hand, the air temperature at the entrance is influenced by the construction interference. The entrance of the tunnel's right tube, which is the construction passage of the left tube, substantially affects the temperature in the tunnel. On the other hand, the natural wind continually blows from the exit to the entrance, which is the key parameter that influences the air temperature in the tunnel. At the tunnel exit, because of the stable wind direction in winter, the low-temperature air outside the tunnel fully transfers the heat energy to the secondary liner and rock masses. Therefore, the temperature of the liner and the rock mass at a certain depth is generally below $0^{\circ} \mathrm{C}$ for a long period. Throughout the year, the temperature, which is generally below $0^{\circ} \mathrm{C}$, is sustained for 210 days in the section $150 \mathrm{~m}$ from the exit. Thus, the temperature fields of the liner and the rock masses at the exit of the tunnel's right tube can be adopted as the evaluation basis for the freeze proofing and heat insulation in this cold-region tunnel. Because of ventilation after the holing-through of the tunnel, heat exchange occurs between the air in the tunnel and the rock mass. With a faster wind speed, more cold air enters the tunnel, and the air temperature in the tunnel decreases accordingly.

\subsubsection{Longitudinal Air Temperature Distribution. As shown} in Figure 13, the air temperature distribution in the longitudinal direction presents an inverted V-shaped pattern from January to March. That is, the highest temperature occurs in the middle section of the tunnel. In addition, the monthly average temperature difference between the tunnel portal and the middle section can be as much as $11^{\circ} \mathrm{C}$. Moreover, the air temperature distribution in the longitudinal direction presents an approximately $\mathrm{W}$-shaped pattern from April to May, and the temperature in the middle section of the tunnel remains high. During this period, the temperature at the exit is rapidly increasing and the temperature difference between the exit and the outdoors is small. Meanwhile, with the minimum temperature occurring in the section that is $150 \mathrm{~m}$ from the entrance, the air temperature distribution at the entrance changes from one way increasing into a $\mathrm{V}$-shaped pattern.

In addition, the air temperature at the entrance increases sharply from January to March, which indicates that the air temperature in the tunnel is significantly higher than that outside the tunnel during the coldest month. The exit air temperature behaves similarly. The primary reason for this phenomenon is that (considering the smaller cross section and the greater length) the heat exchange between the air in the tunnel and the atmosphere outside the tunnel is not significant enough. When the monthly average air temperature is slightly above $0^{\circ} \mathrm{C}$, the air temperature in the tunnel's first $500 \mathrm{~m}$ is lower than at the entrance. Between the section that is $500 \mathrm{~m}$ from the tunnel portal and the middle section of the tunnel, a $0.11^{\circ} \mathrm{C}$ increase in the air temperature per $10 \mathrm{~m}$ is observed in a longitudinal direction from the entrance. Similarly, a $0.07^{\circ} \mathrm{C}$ increase in the air temperature per $10 \mathrm{~m}$ is observed in a longitudinal direction from the exit.

According to previous studies, the climate temperature in one year can be considered to change with time as a sine function (or a cosine function). The extreme temperature of the climate around the Qingshashan tunnel differs according to altitude and location, and the design target time is November 20. Based on the geological investigation and the observational data collected in the field experiments, the air temperature functions in- and outside the tunnel can be obtained as follows.

The air temperature outside the tunnel can be expressed as follows:

$$
T_{-50}=2.3+10 \times \sin \left(\frac{2 \pi t}{365}+\frac{3 \pi}{2}\right) .
$$

The air temperature in the section that is $3 \mathrm{~m}$ from the tunnel portal can be expressed as follows:

$$
T_{3}=3.8+7.9 \times \sin \left(\frac{2 \pi t}{365}+\frac{3 \pi}{2}\right) \text {. }
$$

The air temperature in the section that is $500 \mathrm{~m}$ from the tunnel portal can be expressed as follows:

$$
T_{500}=2.9+8.9 \times \sin \left(\frac{2 \pi t}{365}+\frac{3 \pi}{2}\right) \text {. }
$$

The air temperature in the section that is $1700 \mathrm{~m}$ from the tunnel portal can be expressed as follows:

$$
T_{1700}=6.7+3.8 \times \sin \left(\frac{2 \pi t}{365}+\frac{3 \pi}{2}\right)
$$

where $t$ is the time (s) and $T$ is the climate temperature inor outside the tunnel $\left({ }^{\circ} \mathrm{C}\right)$.

\section{Discussion and Conclusion}

A regressive analysis of temperature field data was conducted based on the long-term field tests at the Qingshashan tunnel, which was located on the eastern Qinghai-Tibet Plateau. The conclusion is as follows: the air temperature outside the tunnel area is lower than that at the tunnel entrance in the whole year, and the average temperature 


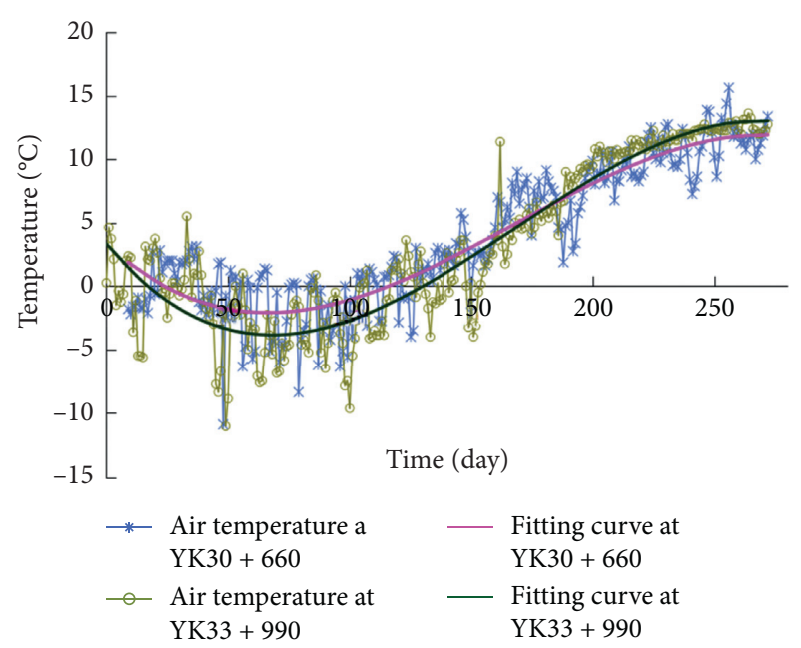

(a)

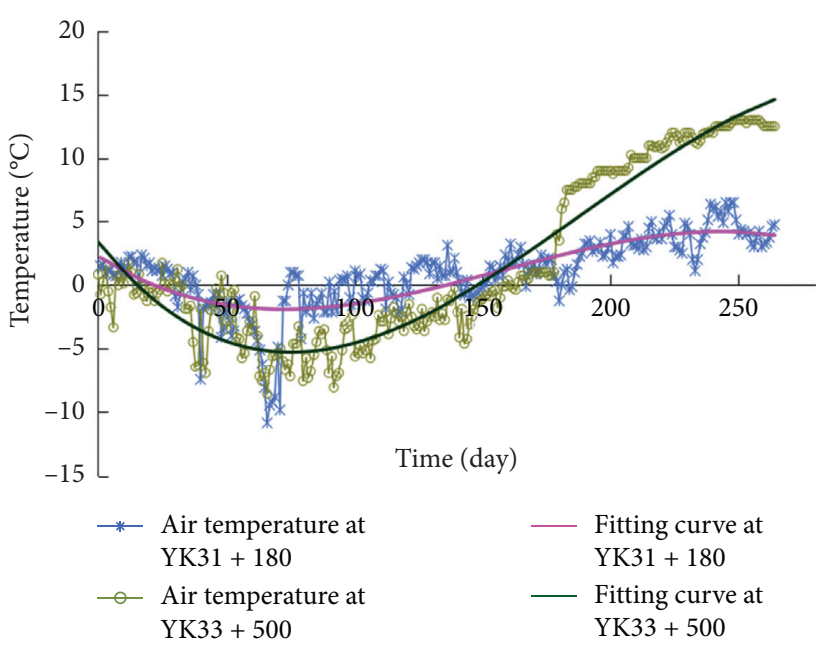

(b)

Figure 12: The air temperature curves in the tunnel with different distance vs. time. (a) Air temperature in the tunnel portal. (b) Air temperature away from the tunnel portal of $500 \mathrm{~m}$.

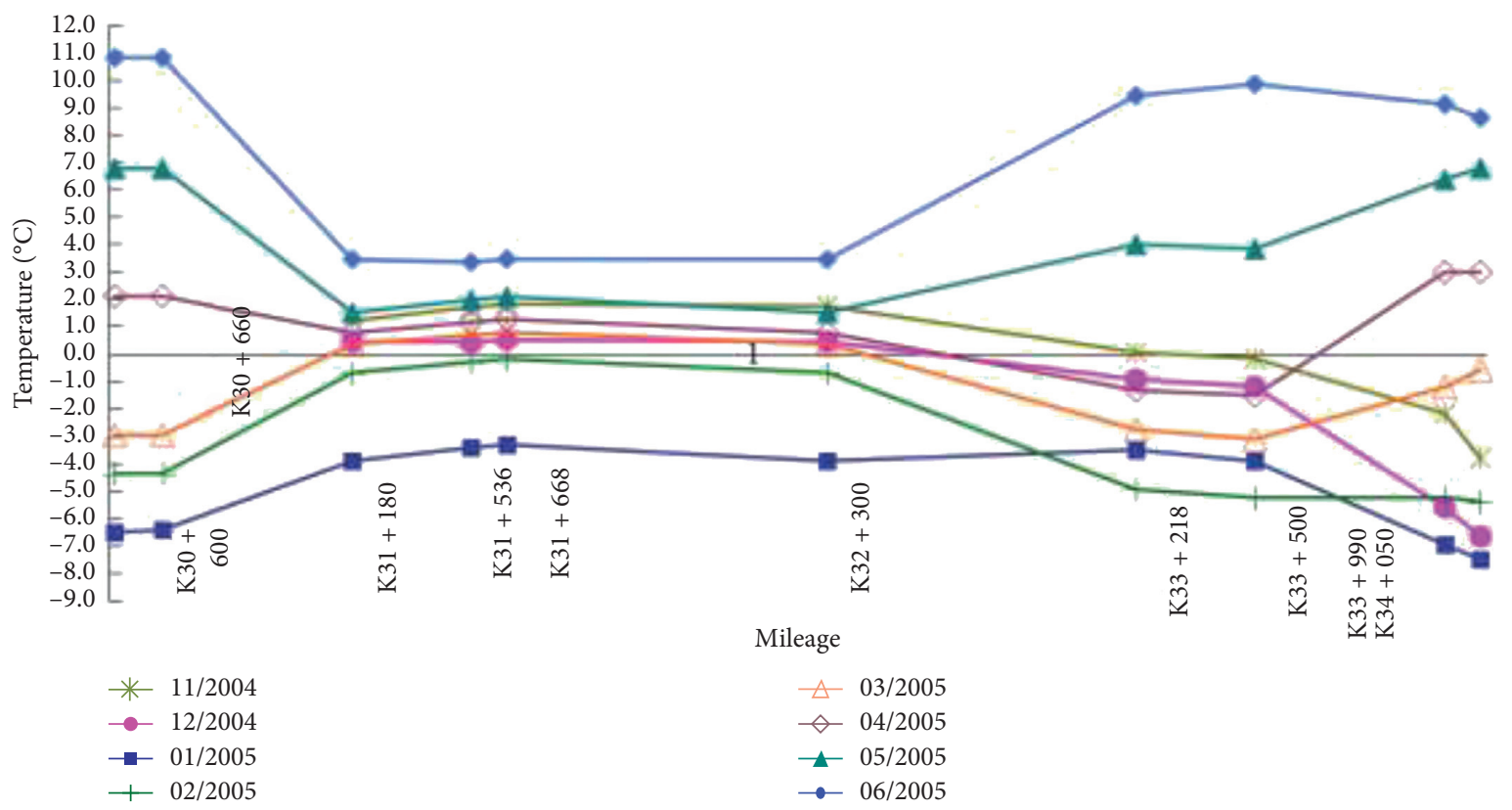

FIgURE 13: Air temperature distribution in longitude along the tunnel.

difference outside the tunnel area reaches the maximum when the temperature is the lowest, and the maximum difference can reach $4^{\circ} \mathrm{C}$. According to the annual wind direction measurement in the tunnel, the wind direction blows from the exit to the entrance in winter, and the wind speed at the exit of the tunnel can reach $2.8 \mathrm{~m} / \mathrm{s}$; the days when the daily average temperature at the exit of the tunnel is lower than $0^{\circ} \mathrm{C}$ each year are about 180 days, and the days at the entrance of the tunnel are about 165 days. The minimum value of the air temperature curve at $500 \mathrm{~m}$ away from the tunnel is 30 days longer than the minimum value of the air temperature curve outside the tunnel. The negative temperature days in the tunnel at $500 \mathrm{~m}$ away from the tunnel exit can reach more than 210 days in the whole year, 30 days longer than the total negative temperature days outside the tunnel entrance. In addition to some extremely low temperatures in the middle of the tunnel, the temperature remained above $0^{\circ} \mathrm{C}$ throughout the year.

During the tunnel operation, because of the increase in the wind speed due to the "piston" effect, the invasion of cold energy is intensified, the temperature in the tunnel environment is decreased, and the ground temperature in the tunnel is decreased. The temperature of the left line is lower than that of the right line, and the inlet of the left line (one side of the air inlet, south side) is significantly lower than that of the right line (one side of the air inlet, south side), 
TABLE 5: Construction experience of similar tunnel projects.

\begin{tabular}{lc}
\hline Name of tunnel & Engineering overview \\
\hline Length: $1530 \mathrm{~m}$; altitude: \\
3650-3900 m; location: Hinterland \\
of Qinghai-Tibet Plateau; \\
completion time: November 28, \\
Dabanshan tunnel \\
1998; monthly average minimum \\
temperature: $-25.6^{\circ} \mathrm{C}$; the \\
maximum depth of frozen is $4.5 \mathrm{~m}$.
\end{tabular}

Length: $655 \mathrm{~m}$; temperature altitude: $3000 \mathrm{~m}$ or above; location:

Yanbian city, Jilin Province;

Xiaopanling tunnel $[37,38]$

completion time: 2000; annual minimum temperature is $-38^{\circ} \mathrm{C}$; the maximum depth of frozen is $1.8 \mathrm{~m}$.

Temperature field information

(1) When the temperature in the tunnel is $-12^{\circ} \mathrm{C}$, the surface of the concrete upper lining is $0.2^{\circ} \mathrm{C}-0.5^{\circ} \mathrm{C}$. (2) The temperature in the tunnel in the cold region changes regularly along the depth, which is approximately a parabolic distribution.

The analysis shows that the maximum frozen depth of surrounding rock changes little along the whole length of the tunnel with a length of about $600 \mathrm{~m}$, and the frozen depth outside the tunnel is larger than that inside the tunnel.
Length: $1338 \mathrm{~m}$; altitude: $4905 \mathrm{~m}$; location: Hinterland of QinghaiTibet Plateau; completion time: October 19, 2002; annual average temperature: $-7^{\circ} \mathrm{C}$; annual minimum temperature is $-41^{\circ} \mathrm{C}$.
(1) The ground temperature of surrounding rock behind the tunnel changes linearly with time and depth. (2) The melting range and the temperature ratio in- and outside the tunnel change linearly during the construction of permafrost

$$
\text { tunnel. }
$$

Qinghai-Tibet railway in China $[39,40]$

(1) The temperature change in- and

Length: $4424 \mathrm{~m}$; altitude: $3500 \mathrm{~m}$; location: Western Sichuan Plateau; completion time: December, 2004; the annual average snow days is $105 \mathrm{~d}$; the maximum snow depth is

$0.47 \mathrm{~m}$; historical lowest

temperature is $-31.1^{\circ} \mathrm{C}$; the maximum depth of frozen is $1.01 \mathrm{~m}$.
Zhegushan tunnel on Highway [41-44] outside the tunnel is periodic, which can be fitted by sine function regression method. (2) After the tunnel is through, the average temperature inside the tunnel decreases by $3-4^{\circ} \mathrm{C}$, after the tunnel is through, the air flow has an impact on the temperature distribution inside the tunnel.
Antifreeze insulation measures

(1) There is no pressure cold-proof drain tunnel under the tunnel's main hole. (2) The tunnel's surface insulation layer is rigid foam profile and rare earth insulation material. (3) The tunnel outlet insulation door, the tunnel outside the circular end buried thermal insulation outlet.

(1) The antifreeze scheme is designed with drainage as the core, using highquality waterproof materials, as well as wave-shaped longitudinal drainage pipes. (2) The drainage technology measures such as thermal insulation outlet are set, and the waterproof and drainage effect of the tunnel is significantly improved.

(1) Strengthen the comprehensive prevention and control measures such as waterproof and drainage, application of heat insulation, and insulation technology. (2) Carry out low-temperature grouting on surrounding rock to achieve the purpose of blocking bedrock fissure water. (3) Set up thermal insulation ditch in the tunnel to lead and drain the water behind the lining.

(1) In the length range where frost damage may occur, the heat insulation layer with surface heat insulation treatment shall be adopted. (2) The proper drainage system shall be adopted, the deep buried water or cold proof ditch shall be adopted to prevent the water discharged from the tunnel from overflowing and road freezing in the portal section due to the inability to discharge from the tunnel.

(1) Cold proof ditch shall be set at the two tunnel openings, respectively, and the distance from the ditch to the outside of the tunnel shall be more than 20 meters. (2) In addition, multiple sets of electric heaters are set in the cold proof ditch to relieve the freezing of drainage channel. (3) Within the length of the hole where freezing damage may occur, the surface heat insulation layer shall be used. while the difference between the outlet of the left line and the inlet of the right line is small.

From the central to the entrance, the temperature in the tunnel decreases by $0.11^{\circ} \mathrm{C}$ every 10 meters along the longitudinal direction; from the central to the exit, the temperature in the tunnel increases by $0.07^{\circ} \mathrm{C}$ every 10 meters.
Those can be expressed by correlation function relations. The National Highway 317 Line Lushan tunnel and the Dabanshan tunnel also showed similar function relations, both of them belonged to long tunnels. The law of the temperature field in the cold-region tunnel with similar altitude, length, wind direction, and wind speed is similar. 
More similarities and differences are shown in Table 5. The research results provided fundamental dates for the investigation of temperature fields and antifreeze insulation measures and references that can be used in the construction of cold-region tunnels [32, 33].

There is a cold proof ditch at the entrance of this long tunnel. Considering the extremely low temperature, there are many electric heaters in the cold proof ditch. For tunnels that may suffer from frost damage, the surface insulation treatment shall be adopted, and then the surrounding rock shall be grouted at low temperature to block the fissure water in the bedrock, and the insulation ditch shall be set in the tunnel to drain the water after lining.

When the central drainage pipe is frozen and thawed, it shall be heated in time to ensure the smooth drainage of the tunnel. Through the temperature field test, the tunnel may be frozen in the range of heat preservation treatment, and the melted water on the back of the lining shall be removed in time, and in principle, the frozen area shall not be heated actively.

\section{Data Availability}

The data used to support the findings of this study are available from the corresponding author upon request.

\section{Conflicts of Interest}

The authors declare that they have no conflicts of interest.

\section{Acknowledgments}

This work was financially supported by the Fundamental Research Funds for Ministry of Transport of the People's Republic of China (no. 2015319812140), Project on Social Development of Shaanxi Provincial Science and Technology Department (nos. 2018SF-382 and 2016SF-412), and Open Fund for Shaanxi Key Laboratory of Geotechnical and Underground Space Engineering (no. YT201905).

\section{References}

[1] X. Tan, W. Chen, D. Yang et al., "Study on the influence of airflow on the temperature of the surrounding rock in a cold region tunnel and its application to insulation layer design," Applied Thermal Engineering, vol. 67, no. 1-2, pp. 320-334, 2014.

[2] L. Duan, Y. Zhang, and J. Lai, "Influence of ground temperature on shotcrete-to-rock adhesion in tunnels," Advances in Materials Science and Engineering, vol. 2019, Article ID 8709087, 16 pages, 2019.

[3] J. Lai, X. Wang, J. Qiu et al., "A state-of-the-art review of sustainable energy based freeze proof technology for coldregion tunnels in China," Renewable and Sustainable Energy Reviews, vol. 82, pp. 3554-3569, 2018.

[4] W. Pei, W. Yu, S. Li, and J. Zhou, "A new method to model the thermal conductivity of soil-rock media in cold regions: an example from permafrost regions tunnel," Cold Regions Science and Technology, vol. 95, pp. 11-18, 2013.

[5] J. Lai, J. Qiu, H. Fan, J. Chen, and Y. Xie, "Freeze-proof method and test verification of a cold region tunnel employing electric heat tracing," Tunnelling and Underground Space Technology, vol. 60, pp. 56-65, 2016.

[6] Z. Zhang, F. Sun, and B. Chen, "Thermal-mechanical coupled analysis for tunnel lining with circular openings," Tunnelling and Underground Space Technology, vol. 102, 2020.

[7] S. Zhang, Y. Lai, X. Zhang, Y. Pu, and W. Yu, "Study on the damage propagation of surrounding rock from a cold-region tunnel under freeze-thaw cycle condition," Tunnelling and Underground Space Technology, vol. 19, no. 3, pp. 295-302, 2004.

[8] Z. C. Wang, X. L. Su, H. P. Lai, and Y. L. Xie, "Conception and evaluation of a novel type support in loess tunnel," Journal of Performance of Constructed Facilities, vol. 34, no. 6, 2020.

[9] X. Zhou, Y. Zeng, and L. Fan, "Temperature field analysis of a cold-region railway tunnel considering mechanical and traininduced ventilation effects," Applied Thermal Engineering, vol. 100, pp. 114-124, 2016.

[10] G. Y. Gao, Q. S. Chen, Q. S. Zhang, and G. Q. Chen, “Analytical elasto-plastic solution for stress and plastic zone of surrounding rock in cold region tunnels," Cold Regions Science and Technology, vol. 72, pp. 50-57, 2012.

[11] P. Y. Zhao, J. X. Chen, Y. B. Luo, L. Chen, Y. Li, and C. Wang, "Investigation of the insulation effect of thermal insulation layer in the seasonally frozen region tunnel: a case study in the zuomutai tunnel China," Advances in Civil Engineering, vol. 2019, Article ID 4978359, 14 pages, 2019.

[12] X. Tan, W. Chen, G. Wu, and J. Yang, "Numerical simulations of heat transfer with ice-water phase change occurring in porous media and application to a cold-region tunnel," Tunnelling and Underground Space Technology, vol. 38, pp. 170-179, 2013.

[13] Y. Lai, Z. Wu, S. Zhang, W. Yu, and Y. Deng, "Study of methods to control frost action in cold regions tunnels," Journal of Cold Regions Engineering, vol. 17, no. 4, pp. 144-152, 2003.

[14] P. Y. Zhao, J. X. Chen, Y. B. Luo et al., "Long-term, real-time and multi-channel distributed temperature monitoring system for tunnels in cold regions," Measurement Science and Technology, vol. 30, no. 6, pp. 44-48, 2019.

[15] J. Chen, X. Deng, Y. Luo, L. He, Q. Liu, and X. Qiao, "Investigation of microstructural damage in shotcrete under a freeze-thaw environment," Construction and Building Materials, vol. 83, pp. 275-282, 2015.

[16] N. I. Johansen, S. L. Huang, and N. B. Aughenbaugh, "Alaska's CRREL permafrost tunnel," Tunnelling and Underground Space Technology, vol. 3, no. 1, pp. 19-24, 1988.

[17] Y. Zhang, Z. Song, and X. Weng, "A constitutive model for loess considering the characteristics of structurality and anisotropy," Soil Mechanics and Foundation Engineering, vol. 58, 2020.

[18] N. K. Bansal, M. S. Sodha, and S. S. Bharadwaj, "Performance of earth air tunnels," International Journal of Energy Research, vol. 7, no. 4, pp. 333-345, 1983.

[19] S. Z. Li, "Temperature measurement study of Xiluoqi No. 2 tunnel of Nenlin line," Tunnel and Underground Engineering, vol. 10, no. 3, pp. 51-60, 1989.

[20] C. X. He, Z. Wu, and L. Zhu, "A convection-conduction model for analysis of the freeze-thaw conditions in the surrounding rock wall of a tunnel in permafrost regions," Science in China Series D: Earth Sciences, vol. 42, no. 1, pp. 1-8, 1999.

[21] Y.-M. Lai, Z. Wu, Y. Zhu, and L. Zhu, "Nonlinear analysis for the coupled problem of temperature and seepage fields in cold regions tunnels," Cold Regions Science and Technology, vol. 29, no. 1, pp. 89-96, 1999.

[22] D. J. Goreing and P. Kumar, "Connective heat transfer in railway embankment ballast," Ground Freezing, vol. 86, pp. 31-36, 2000. 
[23] Q. X. Yan, C. He, and D. Y. Zeng, "Study of temperature field and heat preservation and insulation layer for tunnel in cold area," Journal of Sichuan University: Engineering Science Edition, vol. 37, no. 1, pp. 24-27, 2005.

[24] Y. W. Qin and J. X. Lai, "Arching effect and collapse evolution law of tunnel in boulder-cobble mixed formation," Tunnelling and Underground Space Technology, vol. 104, 2020.

[25] Z. Q. Zhang, K. J. Zhang, W. J. Dong, and B. Zhang, "Study of rock-cutting process by disc cutters in mixed ground based on three-dimensional particle flow model," Rock Mechanics and Rock Engineering, vol. 53, 2020.

[26] S. Suneet, J. Prashantk, and R. Uddin, "Analytical solution to transient heat conduction in polar coordinates with multiple layers in radial direction," International Journal of Thermal Sciences, vol. 47, no. 3, pp. 261-273, 2008.

[27] J. Prashantk, S. Suneet, and R. Uddin, "Analytical solution to transient asymmetric heat conduction in a multilayer annulus," Journal of Heat Transfer, vol. 131, p. 1, 2009.

[28] J. X. Chen and Y. J. Zan, "Field test and analysis of anti freezing thermal protective layer effect of the highway tunnel in cold area," China Journal of Highway and Transport, vol. 14, no. 4, pp. 75-79, 2001.

[29] T. Liu, Y. Xie, Z. H. Feng, Y. B. Luo, K. Wang, and W. Xu, "Better understanding the failure modes of tunnels excavated in the boulder-cobble mixed strata by distinct element method," Engineering Failure Analysis, vol. 117, p. 104712, 2020.

[30] J. X. Chen and Y. B. Luo, "Calculation method of anti-freezing layer thickness in cold region tunnel," Journal of Traffic and Transportation Engineering, vol. 74, pp. 76-79, 2007.

[31] X. J. Zhang, "Field experiment on distribution characters of air temperature and ground temperature in Kunlunshan tunnel of Qinghai-Tibet railway," Chinese Journal of Rock Mechanics and Engineering, vol. 24, no. 6, pp. 1086-1089, 2005.

[32] K. Wu and Z. Shao, "Visco-elastic analysis on the effect of flexible layer on mechanical behavior of tunnels," International Journal of Applied Mechanics, vol. 11, no. 3, p. 20, 2019.

[33] H. Wu, M. Miao, X. Yang, Z. Wang, and T. Liu, "Large deformation characteristics and treatment effect for a deep tunnel in broken phyllite," Environmental Earth Sciences, vol. 79 , no. $16,2020$.

[34] X. L. Wang, J. X. Lai, S. Y. He, R. S. Garnes, and Y. Zhang, "Karst geology and mitigation measures for hazards during metro system construction in Wuhan, China," Natural Hazards, vol. 102, pp. 1909-1935, 2020.

[35] Y. Lai, Z. Wu, Y. Zhu, and L. Zhu, "Nonlinear analyses for the couple problem of temperature, seepage and stress fields in cold region tunnels," Chinese Journal of Geotechnical Engineering, vol. 21, no. 5, pp. 529-533, 1999.

[36] T. Liu, Y. J. Zhong, Z. L. Han, and W. Xu, "Deformation characteristics and countermeasures for a tunnel in difficult geological environment in NW China," Advances in Civil Engineering, vol. 2020, Article ID 1694821, 16 pages, 2020.

[37] J. X. Chen and Y. B. Luo, "Changing rules of temperature field for tunnel in cold area," Journal of Traffic and Transportation Engineering, vol. 8, no. 2, pp. 44-48, 2008.

[38] J. L. Qiu, Y. Q. Lu, J. X. Lai, C. X. Guo, and K. Wang, "Failure behavior investigation of loess metro tunnel under local-highpressure water environment," Engineering Failure Analysis, vol. 115, 2020.

[39] X. F. Zhang, W. B. Yu, and Z. Q. Liu, "Three-dimensional nonlinear analysis for coupled problem of seepage field and temperature field of cold regions tunnels," Yantu Gongcheng
Xuebao (Chinese Journal of Geotechnical Engineering), vol. 28, no. 9, pp. 1095-1100, 2006.

[40] S. Y. He, Y. J. Zhong, J. X. Lai, K. Wang, W. Xu, and C. X. Guo, "Characteristics, prediction methods and countermeasures of rockburst: examples of thirteen traffic tunnels in QinghaiTibet plateau and Qinling-Daba mountainous area in China," Environmental Earth Sciences, vol. 79, no. 15, 2020.

[41] H. Q. Xie, C. He, and Y. L. Li, "Study on insulating layer thickness by phase-change temperature field of highway tunnel in cold region," Chinese Journal of Rock Mechanics and Engineering, vol. 26, no. 2, pp. 4395-4401, 2007.

[42] E. L. Ma, J. X. Lai, L. X. Wang et al., "Review of Cutting-edge sensing technologies for urban underground construction," Measurement, vol. 161, 2020.

[43] H. Li, E. L. Ma, L. X. Wang et al., "Tunnelling induced settlement and treament techniques for a loess metro in Xi'an," Advances in Civil Engineering, vol. 2020, Article ID 1854813, 2020.

[44] H. Wu, C. K. Yao, C. H. Li et al., "Review of application and innovation of geotextiles in geotechnical engineering," $M a$ terials, vol. 13, no. 7, 2020. 